\title{
Management of Dyslipidemia Associated with Anti-Retroviral Therapy in HIV/AIDS Patients
}

\author{
Debrina Kusuma Devi, Erwin Astha Triyono, Musofa Rusli \\ Division of Tropical Medicine, Department of Internal Medicine, Faculty of Medicine, University of Airlangga, Dr. \\ Soetomo General Hospital, Jl Prof Dr Moestopo 47 Surabaya 60132, Indonesia \\ apji@fk.unair.ac.id
}

Keywords: Dyslipidemia, Low-Density Lipoprotein, Human Immunodeficiency Virus, Acquired Immunodeficiency Syndrome, Anti-retroviral

\begin{abstract}
Dyslipidemia is a lipid metabolism disorder characterized by increased and decreased lipid fractions in plasma, including elevated total cholesterol, low-density lipoprotein (LDL) cholesterol, TG, and decreased HDL cholesterol. Dyslipidemia often occurs in patients with Human Immunodeficiency Virus/Acquired Immunodeficiency Syndrome (HIV/AIDS), especially those who have received anti-retroviral therapy (ARV). Various ARVs can cause dyslipidemia and the most common is the Protease Inhibitor group. Dyslipidemia is an important risk factor for cardiovascular events. Management of dyslipidemia in HIVinfected patients receiving antiretroviral therapy includes lifestyle modification, switching of antiretroviral drugs, and the use of lipid-lowering drugs as targeted by the recommendations of the NCEP ATP III.
\end{abstract}

\section{INTRODUCTION}

Human Immunodeficiency Virus (HIV) is a virus that causes Acquired Immunodeficiency Syndrome (AIDS) by attacking white blood cells called CD4 and it can damage the human immune system. According to the CDC (Centers for Disease Control and Prevention), a person is diagnosed with AIDS if it has a CD4 cell count of than 200 cells $/ \mathrm{mm}^{3}$ and suffers one or more opportunistic infections or cancer caused by HIV (Departemen Kesehatan RI, 2006).

A survey conducted by UNAIDS (Joint United Nations Program on HIV AIDS) stated that there were about 35.3 million people worldwide with HIV and 2.3 million of them were new infections in 2012 (UNAIDS, 2013). Directorate General of Disease Control and Environmental Health-Ministry of Health, Republic of Indonesia has conducted a HIV/AIDS case survey in Indonesia until 2014 that showed 150,296 cases of HIV and 55,799 cases of AIDS with deaths in 9,796 cases (Kementerian Kesehatan RI, 2014).

HIV/AIDS has a high mortality rate; however, the mortality of this disease has dropped dramatically since the use of Highly Active AntiRetroviral Therapy (HAART). There was a $4 \%$ reduction in the mortality rate of HIV/AIDS from 2000-2001 in the United States and it continued to decline by $70 \%$ in 2005 . There was a $50 \%$ mortality rate from 2003-2007 in HIV/AIDS patients receiving anti-retroviral therapy in Indonesia. The decrease in HIV/AIDS morbidity and mortality significantly improves the quality of life of people with HIV and AIDS. However, long-term adverse effects of antiretroviral therapy (ARV) are emerging, including dyslipidemia, which is a risk factor for cardiovascular disease (HIV-CASUAL Collaboration, 2010; Bavinger et al., 2013).

Dyslipidemia is common in people with HIV who are receiving anti-retroviral therapy. The prevalence of dyslipidemia in HIV patients receiving antiretroviral therapy varies from $30 \%$ to $80 \%$, depending on the type of drug used. The most common types are hypertriglyceridemia (40-80\%) and hypercholesterolemia (10-50\%) (Sprinz et al., 2010).

A study conducted at Dr. Soetomo General Hospital Surabaya, Indonesia in 2009 on 42 HIV patients receiving ARV treatment showed that serum lipid concentration for total cholesterol was $210.5 \pm$ $68.96 \mathrm{mg} / \mathrm{dL}$, triglyceride level of $216.14 \pm 134.21$ $\mathrm{mg} / \mathrm{dL}$, High Density Lipoprotein (HDL) levels of $42.76 \pm 12.75 \mathrm{mg} / \mathrm{dL}$, and Low-Density Lipoprotein 
(LDL) levels of $144 \pm 71.81 \mathrm{mg} / \mathrm{dL}$ (Rosita et al., 2009).

Many references correlate dyslipidemia in HIV patients with antiretroviral therapy and its effects on the cardiovascular system. Therefore, we aim to further discuss its management because good management is expected to reduce cardiovascular incidences. This study discussed the management of antiretroviral-related dyslipidemia in HIV/AIDS patients that focused on a selection of lipid-lowering drugs.

\section{ANTI-RETROVIRAL THERAPY TYPES}

There are six types of ARV drugs, namely:

1. Nucleoside (NRTI) and nucleotide (NtRTI) reverse transcriptase inhibitors: Zidovudine, lamivudine, emtricitabine, stavudine, didanosine, zalcitabine, abacavir, tenovufir.

2. Non-nucleoside reverse transcriptase inhibitor (NNRTI). Efavirenz, nevirapine, delavirdine

3. Protease inhibitor (PI): Amprenavir/ fosamprenavir, atazanavir, indinavir, lopinavir/ ritonavir, nelfinavir, saquinavir, tipranavir, ritonavir

4. Fusion inhibitor (FI): Enfuvirtide

5. Co-receptor antagonist: Maraviroc, vicriviroc.

6. Integrase inhibitor: Raltegravir (Table 1).
The antiretroviral drugs that are available in Indonesia are Lamivudine, Zidovudine, Tenovufir, Stavudine, Emtricitabine, Efavirenz, Nevirapine, Lopinavir, and Ritonavir. Standard antiretroviral therapy at least uses three types of two different drug types. Treatment using three types of drugs is called HAART which aims to suppress HIV viral replication. WHO recommends the use of two NRTI + one NNRTIs as first-line ARV therapy and two NRTI + boosted PIs as the second line. The first-line and second-line ARV combinations recommended in Indonesia are:

1. First line

- $\mathrm{AZT}+3 \mathrm{TC}+\mathrm{NVP}$ (Zidovudine + Lamivudine + Nevirapine)

- $\mathrm{AZT}+3 \mathrm{TC}+\mathrm{EFV}$ (Zidovudine + Lamivudine + Efavirenz)

- TDF + 3TC (or FTC) + NVP (Tenofovir + Lamivudine or Emtricitabine + Nevirapine

- $\mathrm{TDF}+3 \mathrm{TC}$ (or FTC) + EFV (Tenofovir + Lamivudine or Emtricitabine + Efavirenz)

2. Second line

- $\mathrm{TDF}+3 \mathrm{TC}$ (or FTC) + LPV/r (Tenofovir + Lamivudine or Emtricitabine + Lopinavir/ritonavir)

- $\mathrm{AZT}+3 \mathrm{TC}+\mathrm{LPV} / \mathrm{r}$ (Zidovudine + Lamivudine + Lopinavir/ritonavir)

Those two lines are a combination therapy commonly used in adolescent and adult patients. Selection of drugs and combinations can be adjusted to the condition of each patient (Kementerian Kesehatan RI, 2011).

Table 1: Available Antiretroviral Therapies Based on Types.

\begin{tabular}{|c|c|c|}
\hline ARV Types & 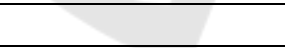 & Examples \\
\hline $\begin{array}{l}\text { Nucleoside and Nucleotide Reverse Transcriptase } \\
\text { Inhibitors (NRTIs) }\end{array}$ & $\begin{array}{l}\text { Abacavir (ABC) } \\
\text { Didanosine (ddI) } \\
\text { Zalcitabine (ddC) }\end{array}$ & $\begin{array}{c}\text { Stavudine (d4T) } \\
\text { Zidovudine (AZT) } \\
\text { Lamivudine (3TC) } \\
\text { Tenofovir (TDF) } \\
\text { Emtricitabine (FTC) }\end{array}$ \\
\hline $\begin{array}{l}\text { Non-Nucleoside Reverse Transcriptase Inhibitors } \\
\text { (NNRTIs) Protease Inhibitor }\end{array}$ & $\begin{array}{c}\text { Delavirdine (DLV) } \\
\text { Etravirine (ETV) } \\
\text { Indinavir (IDV) } \\
\text { Nelfinavir (NFV) } \\
\text { Saquinavir (SQV) } \\
\text { Fosamprinavir (FPV) } \\
\text { Amprenavir (APV) } \\
\text { Tipranavir (TPV) } \\
\text { Darunavir (DRV) }\end{array}$ & $\begin{array}{l}\text { Nevirapine (NVP) } \\
\text { Efavirenz (EFV) } \\
\text { Lopinavir (LPV) } \\
\text { Ritonavir (RTV) }\end{array}$ \\
\hline $\begin{array}{l}\text { Fusion Inhibitor Co-receptor antagonist- CCR5 } \\
\text { antagonist }\end{array}$ & $\begin{array}{l}\text { Enfuvirtide } \\
\text { Maraviroc }\end{array}$ & \\
\hline Integrase Inhibitor & Raltegravir & \\
\hline
\end{tabular}


Table 2: Therapeutic Effect of ARVs to Lipid Profile

\begin{tabular}{|c|c|c|c|c|}
\hline \multicolumn{5}{|c|}{ Currently Recommended First-Line Agents are in Bold } \\
\hline Antiretroviral & Total Cholesterol & LDL-C & HDL-C & Triglyceride \\
\hline \multicolumn{5}{|l|}{ PLs (boosted) } \\
\hline Lopinavir & $\uparrow \uparrow$ & $\uparrow \uparrow$ & $\leftrightarrow / \downarrow$ & 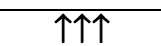 \\
\hline Atazanazir & $\uparrow$ & $\leftrightarrow / \uparrow$ & $\leftrightarrow / \downarrow$ & $\leftrightarrow$ \\
\hline Fosamprenavir & $\uparrow$ & $\uparrow$ & $\leftrightarrow / \downarrow$ & $\uparrow \uparrow$ \\
\hline Saquinavir & $\uparrow \uparrow$ & $\uparrow \uparrow$ & $\leftrightarrow / \downarrow$ & $\uparrow$ \\
\hline Darunavir & $\uparrow$ & $\uparrow$ & $\leftrightarrow / \downarrow$ & $\uparrow$ \\
\hline Tipranavir & $\uparrow \uparrow$ & $\uparrow \uparrow$ & $\leftrightarrow / \downarrow$ & 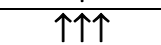 \\
\hline \multicolumn{5}{|l|}{ NNRTIs } \\
\hline Efavirenz & $\uparrow$ & $\uparrow$ & $\uparrow$ & $\uparrow$ \\
\hline Nevirapine & $\uparrow$ & $\uparrow$ & $\uparrow \uparrow$ & $\leftrightarrow / \uparrow$ \\
\hline \multicolumn{5}{|l|}{ NRTIs } \\
\hline Tenofovir & $\leftrightarrow / \uparrow$ & $\leftrightarrow / \uparrow$ & $\leftrightarrow / \uparrow$ & $\leftrightarrow / \uparrow$ \\
\hline Abacavir & $\leftrightarrow / \uparrow$ & $\uparrow$ & $\uparrow$ & $\uparrow$ \\
\hline Lamivudine & $\leftrightarrow$ & $\leftrightarrow$ & $\leftrightarrow$ & $\leftrightarrow$ \\
\hline Zidovudine & $\uparrow$ & $\uparrow$ & $\uparrow$ & $\uparrow \uparrow$ \\
\hline Stavudine & $\uparrow \uparrow$ & $\uparrow \uparrow$ & $\uparrow$ & $\uparrow \uparrow$ \\
\hline \multicolumn{5}{|l|}{ CCR5 Inhibitors } \\
\hline Maraviroc & $\leftrightarrow$ & $\leftrightarrow$ & $\leftrightarrow / \uparrow$ & $\leftrightarrow$ \\
\hline Integrase Inhibitors & 8 & 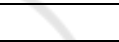 & & \\
\hline Raltegravir & $\leftrightarrow / \uparrow$ & $\leftrightarrow / \uparrow$ & $\leftrightarrow / \uparrow$ & $\leftrightarrow$ \\
\hline
\end{tabular}

Table 3: Category of cardiovascular risk, LDL target, and lipid-lowering drug limits (NCEP ATP III).

\begin{tabular}{llll}
\hline \multicolumn{1}{c}{ Risk Category } & \multicolumn{1}{c}{ LDL-C Goal } & Initiate TLC & \multicolumn{1}{c}{ Consider Drug Therapy } \\
\hline $\begin{array}{l}\text { High risk: CHD or CHD } \\
\text { risk equivales (10-years risk }\end{array}$ & $<100 \mathrm{mg} / \mathrm{dL}$ (optional goal: & $\geq 100 \mathrm{mg} / \mathrm{dL}$ & $\geq 100 \mathrm{mg} / \mathrm{dL}$ \\
$>20 \%)$ & & $\begin{array}{l}(<100 \mathrm{mg} / \mathrm{dL} \text { : consider drug } \\
\text { options })\end{array}$ \\
$\begin{array}{l}\text { Moderately high risk: } 2+ \\
\text { risk (10-year risk } 10 \%)\end{array}$ & $(<130 \mathrm{mg} / \mathrm{dL})$ & $\geq 130 \mathrm{mg} / \mathrm{dL}$ & $\geq 160 \mathrm{mg} / \mathrm{dL}$ \\
Lower risk: $0-1$ risk factor & $<130 \mathrm{mg} / \mathrm{dL}$ & $\geq 160 \mathrm{mg} / \mathrm{dL}$ & $\begin{array}{l}\geq 190 \mathrm{mg} / \mathrm{dL} \\
(160-189: \text { LDL-lowering drug } \\
\end{array}$ \\
& & & optional) \\
\hline
\end{tabular}

CHD: Coronary Heart Disease. Major risk factors: cigarette smoking, hypertension (BP $>140 / 90 \mathrm{mmHg}$ or on antihypertensive medication); low HDL cholesterol $(<40 \mathrm{mg} / \mathrm{dl})$; family history of premature CHD (CHD in male firstdegree relative $<55$ years; CHD in female first-degree relative $<65$ years, and age (men $>45$ years, women $>55$ years). TLC: Therapeutic Lifestyle Changes. LDL: Low-Density Lipoprotein (Grundy et al., 2004)

\section{DISLIPIDEMIA IN HIV INFECTION}

Dyslipidemia is defined as a lipoprotein metabolism abnormality characterized by an increase or decrease in plasma lipoprotein fraction. The major lipoprotein fraction abnormalities are the increase in total cholesterol, LDL cholesterol, triglycerides, and decreased HDL cholesterol. Dyslipidemia is a major risk factor for cardiovascular disease.

Factors that cause dyslipidemia in HIV patients include age, male sex, family history of cardiovascular disease, poor diet, obesity, and poor lifestyle (Aberg and Malvestutto, 2011).
Dyslipidemia in HIV infection is characterized by a decrease in HDL cholesterol, LDL, and total cholesterol, and an increase in TG. Hypertriglyceridemia that occurs in HIV infection is a response to the chronic inflammatory process caused by the HIV virus. The inflammatory mediators involved are interferon- $\alpha$ (IFN- $\alpha$ ), interleukin-6 (IL-6) which can increase lipogenesis. There is an increased activity of protein transfer cholesterol ester (CETP) in HIV infection in which CTEP plays a role in the transfer of cholesterol ester from HDL to apolipoprotein-B. This explains the reason why HDL cholesterol levels are low in HIV infection. 
Dyslipidemia in HIV patients may also be part of the lipodystrophy syndrome. The lipodystrophy syndrome is a cluster of clinical symptoms due to abnormal fat distribution in HIV patients receiving antiretroviral therapy. Lipodystrophy is characterized by elevated triglycerides, total cholesterol, apoprotein B, or hyperinsulinemia. The lipodystrophy syndrome is affected by the length of treatment with ARVs and the age of the patient. This syndrome is characterized by changes in body fat composition in the form of lipoatrophy (decreased subcutaneous fat tissue due to an inability to store peripheral fat with increased distribution to visceral fat) that often occurs in the face, legs and buttocks and lipohypertrophy (accumulation of visceral fat tissue) in the form of gynecomastia and "buffalo hump".

There is an increased release of cytokines in lipodystrophy such as Tumor Necrosis Factor (TNF) and interleukin-6 (IL-6) as well as free fatty acids. Those with a decrease of adipose tissue could lead to lipotoxicity and fat deposition in the liver and muscle. The deposition of fat in the liver causes steatohepatitis and fat deposition in muscles plays a role in metabolic changes, especially insulin resistance. The presence of lipotoxicity also affects pancreatic function and leads to insulin resistance, glucose tolerance disorder, and dyslipidemia. These metabolic changes increase the risk of the occurrence of cardiovascular disease (Caron et al., 2010; Estrada and Portilla, 2011; Feeney and Patrick, 2011). Detailed informations can be seen on table 1 and figure1.

Several PI mechanisms are involved in the process of dyslipidemia, including:

1. Barriers to proteasome in hepatocytes stimulate TG synthesis and cholesterol.

2. Barriers to Glucose Transporter-4 (GLUT-4) in skeletal muscle and adipocyte tissue result in impaired glucose absorption and lipid metabolic disorders.

3. Barriers to the regulatory sterol translocation process in the process of glucose synthesis and adipocyte differentiation reduce adipocyte differentiation which affects fat distribution and peripheral lipoatrophy.

4. Barriers to SREBP-1 can increase lipogenesis and VLDL resulting in dyslipidemia. Enzyme Binding Protein-1 (SREBP-1), an NRTI class depleting mitochondrial DNA of peripheral adipocyte tissue, accelerates apoptosis and reduces peripheral lipid storage capacity resulting in peripheral lipoatrophy and dyslipidemia. Efavirenz, an NNRTI, can directly induce the occurrence of dyslipidemia (Andrew, 2003) (Figure 2).

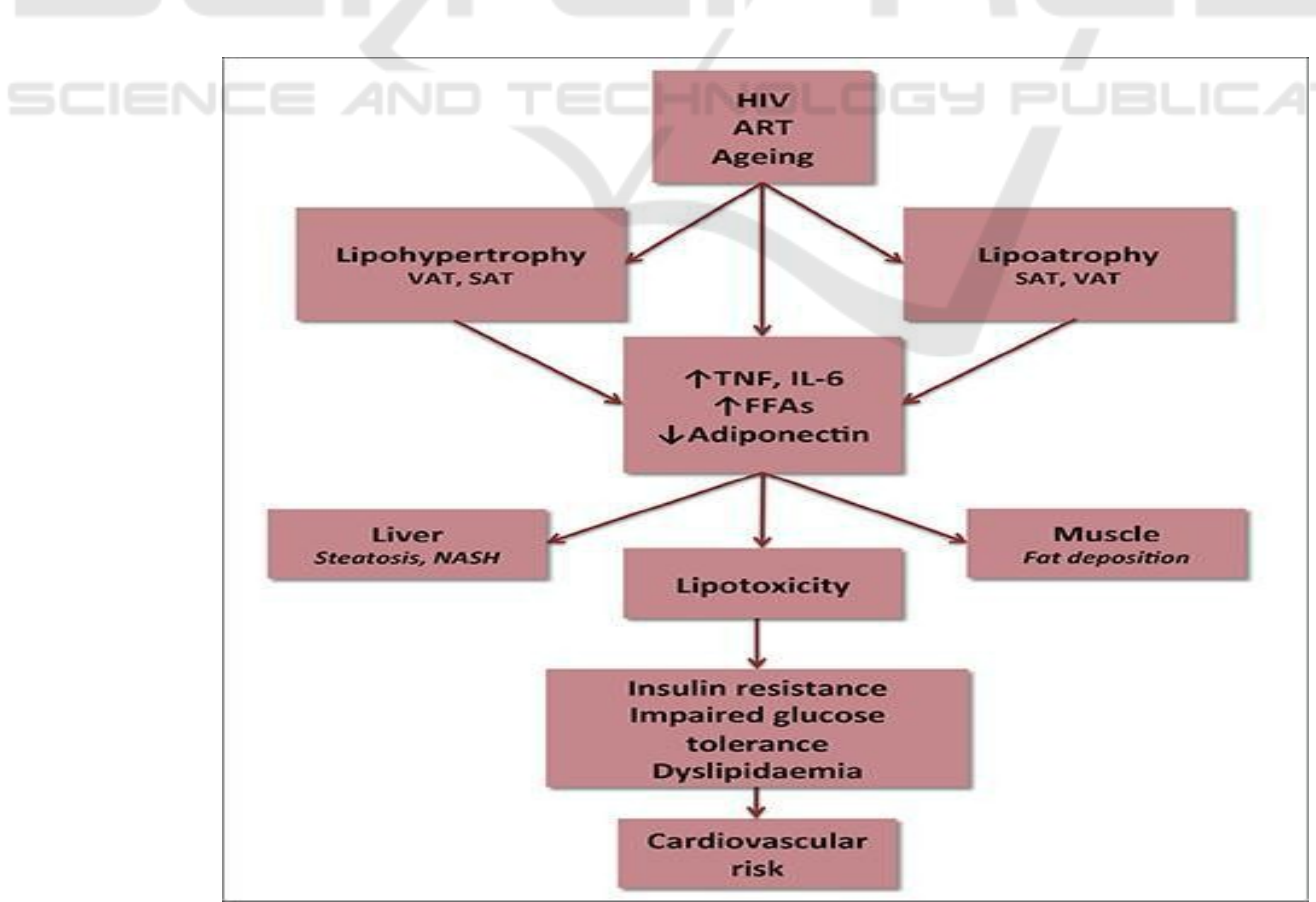

Figure 1. Metabolic changes due to lipodystrophy (Caron et al., 2010) VAT = visceral adipose tissue; SAT = subcutaneous adipose tissue; TNF $=$ tumor necrosis factor; IL-6 = interleukin-6; FFAs $=$ free fatty acids; NASH $=$ Non-alcoholic steatohepatitis. 


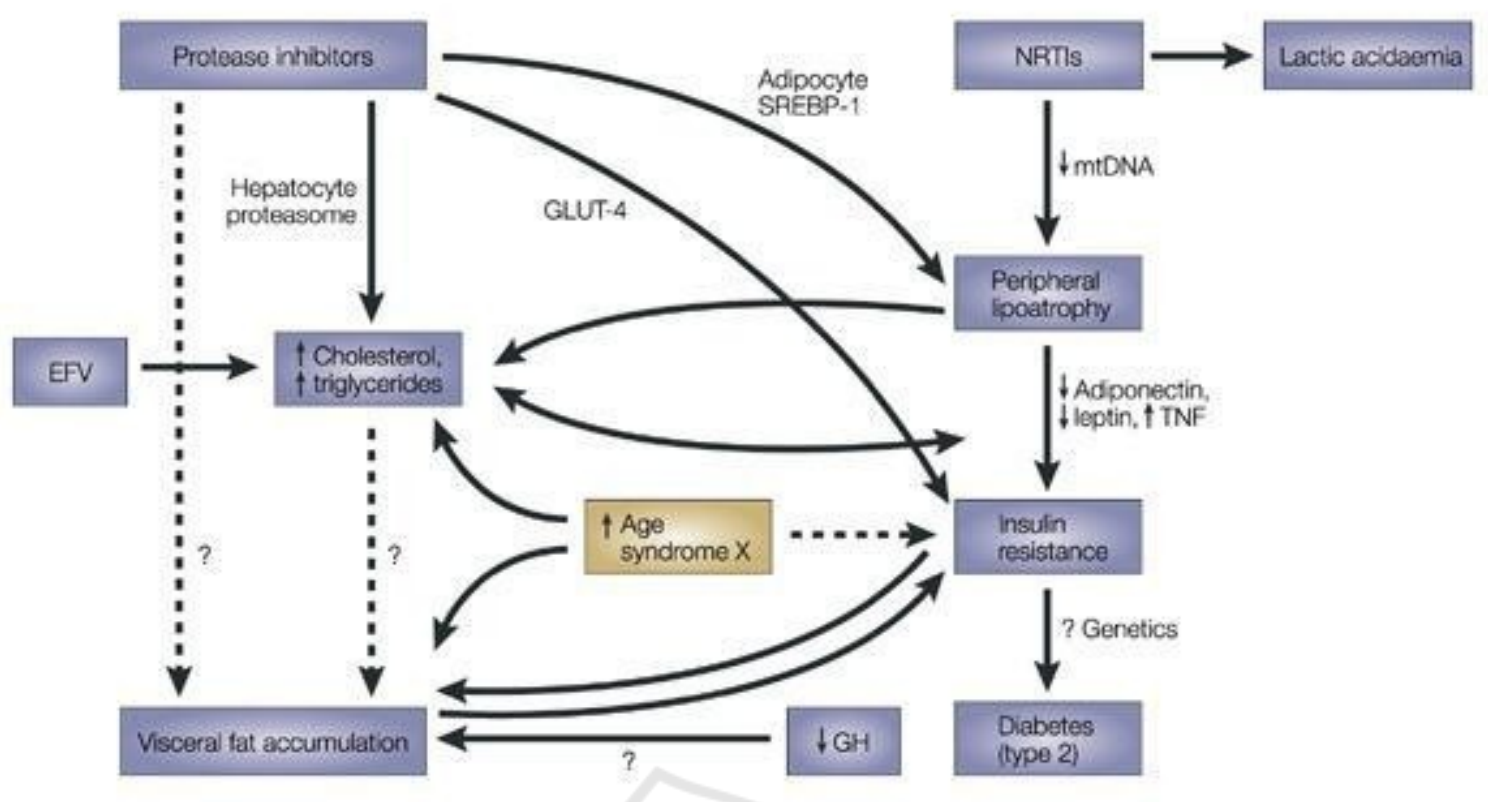

Nature Reviews | Drug Discovery

Figure 2: Pathogenesis of lipodystrophy, dyslipidemia, insuline resistance (Andrew, 2003).

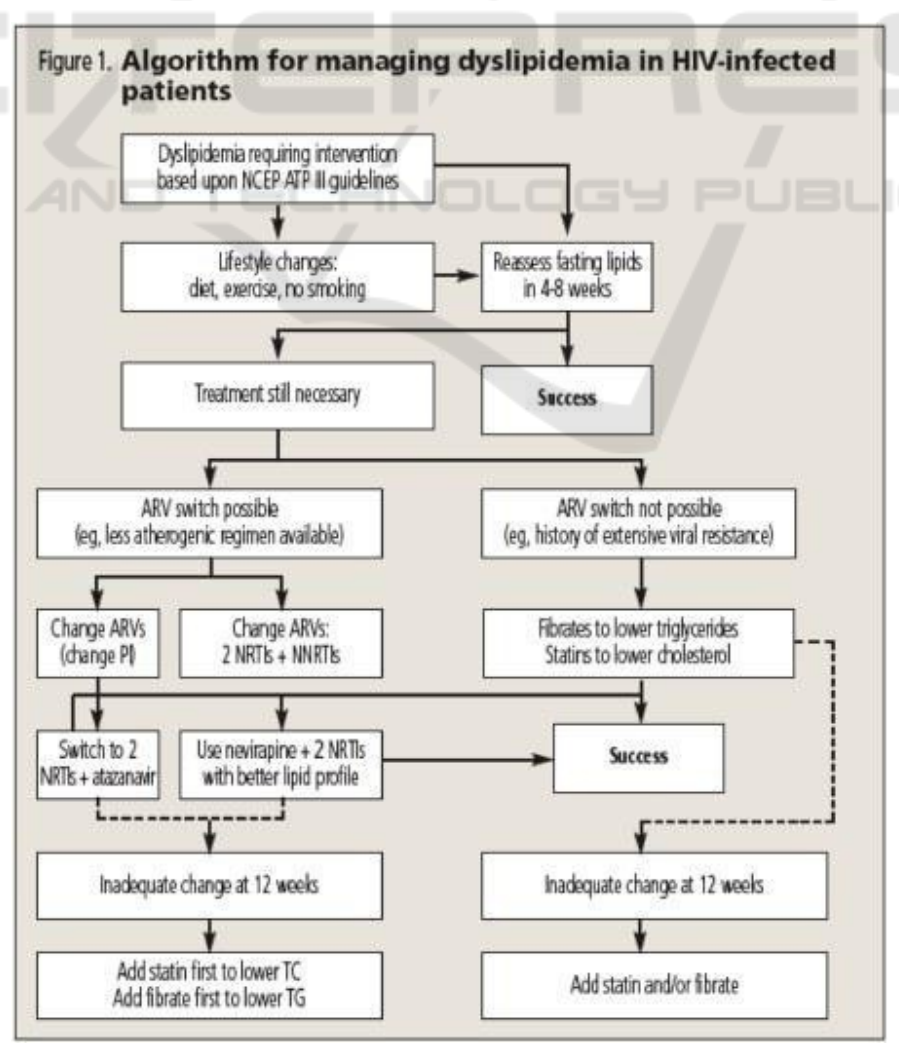

Figure 3: Algorithm for managing dyslipidemia in HIV-infected patients. 


\begin{tabular}{|c|c|c|c|c|c|c|c|c|c|c|c|c|c|c|c|c|c|c|c|c|}
\hline & & ATVir & DRV/r & FPVir & IDVir & LPVir & SQVir & EFV & ETV & NVP & RPV & MVIC & DTG & EVG/c & RAL & $\mathrm{ABC}$ & FTC & $3 \mathrm{TC}$ & TDF & ZDV \\
\hline \multirow{4}{*}{ 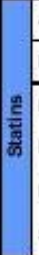 } & Atorvastafin & 1 & $t$ & $1153 \%$ & 1 & $1490 \%$ & $\uparrow$ & $143 \%$ & $137 \%$ & 1 & $\rightarrow$ & $\rightarrow$ & $\rightarrow$ & $\uparrow$ & $\rightarrow$ & $\leftrightarrow$ & $\hookrightarrow$ & $\rightarrow$ & $\rightarrow$ & $\rightarrow$ \\
\hline & Fluvastatin & $\leftrightarrow$ & $\leftrightarrow$ & $\rightarrow$ & 1 & $\leftrightarrow$ & $\uparrow$ & $\uparrow$ & $\uparrow$ & $\rightarrow$ & $\rightarrow$ & 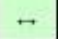 & 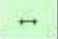 & $\leftrightarrow$ & $\rightarrow$ & $\rightarrow$ & $\rightarrow$ & $\rightarrow$ & $\rightarrow$ & $\leftarrow$ \\
\hline & Pravastatin & $\leftarrow$ & $181 \%$ & $\rightarrow$ & 1 & $\leftrightarrow$ & $150 \%$ & $144 \%$ & 1 & $\rightarrow$ & $\rightarrow$ & $\leftrightarrow$ & $\leftrightarrow$ & $\leftrightarrow$ & $\mapsto$ & $\leftrightarrow$ & 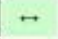 & $\rightarrow$ & $\rightarrow$ & $\leftarrow$ \\
\hline & Rosu vastatin & $1213 \%$ & $148 \%$ & $18 \%$ & $\uparrow$ & $1107 \%$ & $\uparrow$ & $\leftrightarrow$ & $t$ & $\rightarrow$ & $\rightarrow$ & $\leftrightarrow$ & $\rightarrow$ & $148 \%$ & $\rightarrow$ & $\rightarrow$ & $\rightarrow$ & $\leftrightarrow$ & $\rightarrow$ & $\rightarrow$ \\
\hline \multirow{5}{*}{ 兽 } & Bezafibrate & $\leftrightarrow$ & $\rightarrow$ & $\rightarrow$ & $\rightarrow$ & 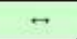 & $\leftrightarrow$ & $\leftrightarrow$ & $\rightarrow$ & $\rightarrow$ & $\rightarrow$ & $\leftrightarrow$ & $\rightarrow$ & $\rightarrow$ & $\rightarrow$ & $\rightarrow$ & $\rightarrow$ & 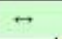 & $\rightarrow$ & $\rightarrow$ \\
\hline & Clofibrate & $\rightarrow$ & $\rightarrow$ & $\rightarrow$ & $\rightarrow$ & $\rightarrow$ & $\rightarrow$ & $\rightarrow$ & $\rightarrow$ & $\rightarrow$ & $\rightarrow$ & $\rightarrow$ & $\rightarrow$ & $\leftrightarrow$ & $\rightarrow$ & $\rightarrow$ & $\rightarrow$ & $\neg$ & $1 \pi$ & $\rightarrow$ \\
\hline & Fenofibrate & $\rightarrow$ & $\rightarrow$ & $\rightarrow$ & $\rightarrow$ & $\rightarrow$ & $\leftrightarrow$ & $\rightarrow$ & $\rightarrow$ & $\rightarrow$ & $\rightarrow$ & $\leftrightarrow$ & $\rightarrow$ & $\rightarrow$ & $\rightarrow$ & 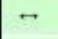 & $\rightarrow$ & $\leftrightarrow$ & $\rightarrow$ & $\rightarrow$ \\
\hline & Gemfibrozil & $t$ & + & 1 & $t$ & $141 \%$ & t & $\leftrightarrow$ & $\rightarrow$ & $\rightarrow$ & $\rightarrow$ & $\leftrightarrow$ & $\pi$ & $\leftrightarrow$ & $\uparrow$ & 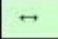 & $\rightarrow$ & 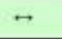 & $\rightarrow$ & $\rightarrow$ \\
\hline & Ezetimibe & $t^{2}$ & $\rightarrow$ & $\rightarrow$ & $\rightarrow$ & $\rightarrow$ & $\rightarrow$ & $\rightarrow$ & $\rightarrow$ & $\rightarrow$ & $\rightarrow$ & $\rightarrow$ & $\rightarrow$ & $\rightarrow$ & $\rightarrow$ & $\rightarrow$ & - & $\rightarrow$ & - & $\rightarrow$ \\
\hline
\end{tabular}

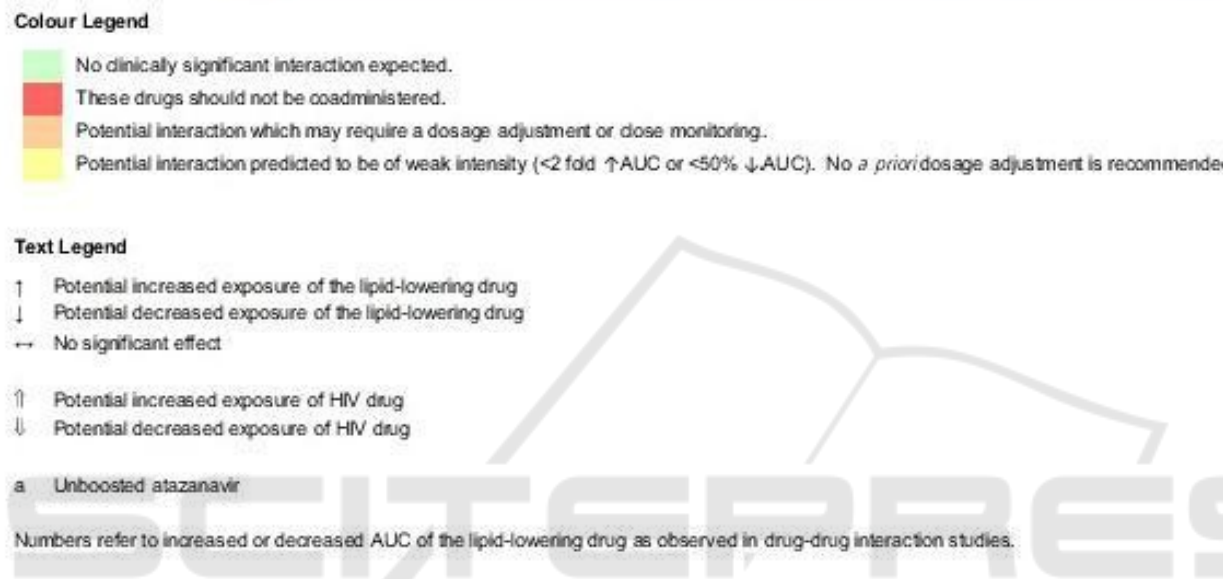

Figure 4: Interaction of ARV with lipid-lowering drugs.

\section{DYSLIPIDEMIA MANAGEMENT}

The American College of Cardiology and The American Heart Association (ACC/AHA) in 2013 released a recommendation regarding the management of dyslipidemia. However, the recommendations issued by the ACC/AHA do not include the management of dyslipidemia in patients with HIV infection; thus, the management of dyslipidemia in HIV patients continues to use recommendations in accordance with NCEP ATP III (Coffey, 2014; Stone et al., 2013).

Evaluation and management of dyslipidemia in HIV-infected patients receiving antiretroviral therapy include lifestyle modification, switching of antiretroviral drugs, and the use of lipid-lowering drugs as targeted by the recommendations of NCEP ATP III. The examination of total cholesterol, LDL, HDL, and TG should be checked before starting antiretroviral therapy and should be evaluated periodically. Lifestyle modifications such as smoking cessation, diet, and exercise are the initial recommendations. If the lipid target is still not reached then it is necessary to replace antiretroviral drugs or use lipid-lowering drugs (Estrada and Portilla, 2011; Dube et al., 2003; Grundy et al., 2004) (Table 3).

The use of lipid-lowering drugs may interact pharmacokinetically with antiretroviral drugs; thus, the selection of lipid-lowering drugs is important. Low-dose atorvastatin and rosuvastatin may be used with protease inhibitors with monitoring of sideeffects. If there are no side-effects and lipid levels have not reached the target after 6-8 weeks of usage, then the doses of atorvastatin and rosuvastatin may be increased. Use of simvastatin and lovastatin is not recommended when combined with protease inhibitors. Pravastatin levels decrease by about 50\% when used with protease inhibitors; thus, it is necessary to increase the dose to improve the efficacy.

Atorvastatin, lovastatin, pravastatin, and simvastatin levels decrease when used with NNRTIs 
(EFV and NVP). Ezetimibe can reduce LDL levels by $10-20 \%$ and it has synergistic effects when combined with a statin class. Fibrates (gemfibrozil) or fenofibrate is useful for lowering TG levels. Fibrate can reduce TG levels by $50 \%$ and increase HDL by $5-10 \%$.

Fibrates generally have little interaction with protease inhibitors because the fibrates are not metabolized in the cytochrome P450. Fibrates can be combined with statins to increase the effect on decreased TG up to normal levels. Fenofibrate can reduce TG levels by more than $50 \%$. If combined with pravastatin, it can achieve lipid targets according to NCEP ATP III in patients with HIV(Estrada and Portilla, 2011; Calza et al., 2003; Wohl et al., 2008) (Figure 3 \& 4).

\section{PROGNOSIS}

The chronic inflammatory process in HIV patients plays a role in increasing the risk of coronary artery disease. The incidence of acute myocardial infarction is quite high in HIV patients, both ARV and non-ARV. The risk of acute myocardial infarction associated with dyslipidemia in HIV patients receiving PI therapy increases by 2.13 times, NRTI increases by 1.21 times in Stavudine use, the use of Lamivudine and Zidovudine increases by 1.05 times, and the NNRTI group of Efavirenz increases by 1.02 times compared to HIV patients that do not receive antiretroviral therapy (Bavinger et al., 2013).

\section{CONCLUSION}

HIV/AIDS has a high mortality rate; however, the mortality of this disease has dropped dramatically since the use of Highly Active Anti-Retroviral Therapy (HAART). Dyslipidemia is common in people with HIV who are receiving anti-retroviral therapy. The incidence of acute myocardial infarction is quite high in HIV patients, both ARV and non-ARV.

\section{REFERENCES}

Aberg, J., \& Malvestutto, C. D. 2011. Management Of Dyslipidemia In Hiv-Infected Patients. Clin Lipidol, 6, 447-462.
Andrew, C. 2003. . Toxicity Of Antiretroviral Therapy And Implications For Drug Development. . Nature Reviews Drug Discovery, , 2: , 624-634.

Bavinger, C., , , Bendavid, E., Niehaus, K., Olshen, R. A., . \& Olkin, I. 2013. Risk Of Cardiovascular Disease From Antiretroviral Therapy For Hiv: . A Systematic Review. Plos One, , 8.

Calza, L., Manfredi, R. \& Chiodo, F. 2003. . Statins And Fibrates For The Treatment Of Hyperlipidaemia In Hiv-Infected Patients Receiving Haart. Aids, , 17: , 851-9.

Caron, D., M., , Lagathu C. \& Boccara, F. 2010. . HivAssociated Lipodystrophy: From Fat Injury To Premature Aging. Trends Mol Med, , 16, :218-229.

Coffey, S., , 2014. 2014. Dyslipidemia. . In Guide For Hiv/Aids Clinical Care. Rockville: U.S.Department Of Health And Human Services, , 339-349.

Departemen Kesehatan Ri 2006. . Situasi Hiv/Aids Di Indonesia. . Jakarta: : Pusat Data Dan Informasi Departemen Kesehatan Ri.

Dube, M. P., Stein, J. H., Aberg, J. A., Fichtenbaum, C. J. \& Gerber, J. G. 2003. . Guidelines For The Evaluation And Management Of Dyslipidemia In Hiv-Infected Adults Receiving Antiretroviral Therapy: Recommendation Of The Hiv Medical Association Of The Infectious Disease Society Of America And The Adult Aids Clinical Trials Group. Clin Infect Dis, 37:613-627.

Estrada, C. \& Portilla, J. 2011. . Dyslipidemia Related Antiretroviral Therapy. . Aids Rev, , 13:, 49-56.

Feeney, E. R. \& Patrick, W. 2011. Hiv And HaartAssociated Dyslipidemia. . Cardiovasc Med J, ,49-63.

Grundy, S., J., C., Merz, C., Brewer, H. B. \& Clark, L. T., . 2004. Implications Of Recent Clinical Trials For The National Cholesterol Education Program Adult Treatment Panel Iii Guidelines. . Circulation,, 110, 227-239.

Hiv-Casual Collaboration 2010. . The Effect Of Combined Antiretroviral Therapy Overall Mortality In HivInfected Individuals. Aids, , 24: , 123-37.

Kementerian Kesehatan Ri 2011. Pedoman Nasional Tatalaksana Klinis Infeksi Hiv Dan Terapi Antiretroviral Pada Orang Dewasa Dan Remaja. Jakarta: Kementerian Kesehatan Ri.

Kementerian Kesehatan Ri 2014. . Statistik Kasus Hiv/Aids Di Indonesia Dilapor S/D September2014. . Sumber : Direktorat Jenderal Pengendalian Penyakit Dan Penyehatan Lingkungan Kementerian Kesehatan Republik Indonesia.

Rosita, C., Hans, L. \& Desy, H., 2009. . Profil Lipid Penderita Hiv/Aids Yang Mendapat Pengobatan Arv. . Media Jurnal Berkala Ilmu Kesehatan Kulit\&Kelamin, Vol 21.

Sprinz, E., , , Rosmeri, K. \& Regina, K. 2010. Dyslipidemia In Hiv-Infected Individuals. . Braz $J$ Infect Dis, , 14.

Stone, N. J., Robinson, J., Lichtenstein, A. H., Bairey, M. \& Blum, J. B. 2013. . Acc/Aha Guideline On The Treatment Of Blood Cholesterol To Reduce Atherosclerotic Cardiovascular Risk In Adults: A 
Report Of The American College Of Cardiology/American Heart Association Task Force On Practice Guidelines. . J Am Coll Cardiol 2013 Nov 7.

Unaids 2013. . Global Report Unaids Report On The Global Aids Epidemic 2013. Switzerland:Unaids.

Wohl, D. A., Waters, D. \& Simpson, R. J. 2008. Ezetimibe Alone Reduces Low-Density Lipoprotein Cholesterol In Hiv-Infected Patients Receiving Combination Antiretroviral Therapy. . Clin Infect Dis, , 47: , 1105-8. 